DOI: $10.5216 /$ rs.v5.64069

\title{
PANORAMA HISTÓRICO DOS ESTUDOS TOPONÍMICOS EM LIBRAS NO BRASIL
}

\author{
HISTORICAL OVERVIEW OF TOPONYMIC STUDIES IN LIBRAS \\ IN BRAZIL
}

\author{
Alexandre Melo de Sousa * \\ Liliane Lemos Santana Barreiros**
}

\section{Resumo}

A toponímia é a área da linguística que se dedica aos nomes próprios de lugares. Os estudos toponímicos relacionados às línguas de modalidade oral-auditiva são tradicionais no Brasil. Em línguas de modalidade visual-espacial, no entanto, são raros. O presente artigo objetiva fazer um apanhado das pesquisas que se dedicam à toponímia em Libras em território brasileiro, observando as contribuições de cada estudo e as perspectivas futuras para a área.

Palavras-chave: Toponímia. Libras. Pesquisas. Brasil.

\section{Considerações iniciais: os estudos toponímicos no Brasil}

No âmbito dos estudos toponímicos brasileiros, destacam-se as contribuições teóricometodológicas de Maria Vicentina do Amaral Dick que, desde a década de 80, tem desenvolvido e orientado pesquisas que descrevem o perfil toponímico dos diversos espaços geográficos em solo brasileiro. Essas pesquisas, entre outros fatores, têm alimentado os diversos Atlas Toponímicos em desenvolvimento em diferentes estados. O projeto de Atlas Toponímico do Brasil (ATB), criado e coordenado por Dick, numa perspectiva macrotoponímica, abrange todos os estados do Brasil e tem como variante primeira o Projeto ATESP (Atlas Toponímico do Estado de São Paulo).

A partir dessa proposta maior e sob a supervisão de Dick, surgiram outros projetos: o Projeto Atlas Toponímico do Estado de Mato Grosso do Sul (ATEMS), vinculado à

\footnotetext{
*Universidade Federal do Acre (UFAC), Rio Branco, Acre, Brasil. E-mail: alexlinguista@gmail.com

** Universidade Estadual de Feira de Santana (UEFS), Feira de Santana, Bahia, Brasil. E-mail: lilianebarreiros@uefs.br
} 
Universidade Federal de Mato Grosso do Sul (UFMS), desenvolvido e coordenado por Aparecida Negri Isquerdo; o Projeto Atlas Toponímico do Estado de Minas Gerais (ATEMIG), vinculado à Universidade Federal de Minas Gerais (UFMG) e coordenado por Maria Cândida Trindade Costa de Seabra; o Projeto Atlas Toponímico do Paraná (ATEPAR), vinculado à Universidade Estadual de Londrina (UEL) e coordenado por Maria Antonieta Carbonari de Almeida até 2004; o Projeto Atlas Toponímico do Tocantins (ATT) e o Projeto Atlas Toponímico de Origem Indígena do Tocantins (ATITO), ambos vinculados à Universidade Federal do Tocantins (UFT) e coordenados por Karylleila dos Santos Andrade; o Projeto Atlas Toponímico do Estado do Maranhão (ATEMA), vinculado à Universidade Estadual do Maranhão (UEMA) e coordenado por Maria Célia Dias de Castro; o Projeto Atlas Toponímico da Amazônia Ocidental Brasileira (ATAOB), vinculado à Universidade Federal do Acre (UFAC) e coordenado por Alexandre Melo de Sousa; e o Projeto Atlas Toponímico da Bahia (ATOBAH), vinculado à Universidade do Estado da Bahia (UNEB) e coordenado por Celina Márcia de Souza Abbade.

Todos os Atlas citados descrevem a toponímia com base na análise dos signos toponímicos, seja na sua estrutura de formação, seja na sua perspectiva motivacional, destacando os aspectos que influenciaram o nomeador no ato de batismo dos diferentes espaços geográficos em suas respectivas áreas de pesquisa. No entanto, com exceção do Projeto ATAOB, todos os outros Atlas têm se dedicado exclusivamente à nomeação espacial em línguas orais (língua portuguesa ou as várias línguas indígenas brasileiras).

Vale lembrar que, assim como ocorre nas línguas de modalidade oral-auditiva, como afirmam Sousa e Quadros (2019a; 2019b), nas línguas de modalidade visual-espacial ocorre também o processo de nomeação espacial, e os sinais toponímicos refletem a cosmovisão dos usuários da língua e são passíveis de análise estrutural (do signo) e motivacional, com relação aos aspectos visuais que influenciaram na escolha (ou mesmo na criação) dos sinais no ato de nomeação (batismo) dos espaços.

A proposta do presente artigo é dar notícias dos diferentes estudos toponímicos em línguas de sinais desenvolvidos no Brasil e suas contribuições para as pesquisas do léxico, para as pesquisas em línguas de sinais, para as pesquisas sobre educação e cultura surda e para a descrição da língua brasileira de sinais (Libras).

\section{A língua brasileira de sinais (Libras)}

A Lei 10.436, de 2002, reconheceu a Libras como "língua dos surdos brasileiros". A 
regulamentação da referida Lei se deu por meio do Decreto 5.626/2005, "que apresenta as ações para aplicar as políticas linguísticas e educacionais com vistas a preservar e disseminar a Língua Brasileira de Sinais" (QUADROS, 2017, p. 34). Contudo, é preciso considerar que as línguas de sinais não são as mesmas em todos os lugares (existe a língua de sinais americana, a língua de sinais francesa, a língua gestual portuguesa etc.) e que as línguas de sinais são produzidas em modalidades diferentes das línguas orais - as primeiras, segundo Crasborn $(2012$, p. 4) "são articuladas por movimentos corporais percebidos visualmente" $1 \mathrm{e}$ as segundas "são produzidas pela articulação vocal e percebidas pela audição" 2 (CRASBORN, 2012, p. 4, Trad. Carlos Roberto Ludwig). É importante destacar que as diferenças de modalidade causam diferenças estruturais e ainda:

[...] que a percepção auditiva é mais bem direcionada ao processamento de pequenos detalhes temporais do que a percepção visual, e visto que os articuladores manuais na sinalização se movem mais lentamente do que os articuladores orais na fala, seria possível prever a riqueza de informações simultâneas nas línguas de sinais ${ }^{3}$ (CRASBORN, 2012, p. 4, Trad. Carlos Roberto Ludwig).

Embora sejam de modalidades diferentes, as línguas de sinais são estruturadas em todos os aspectos: lexical, fonológico, morfológico, sintático e semântico - assim como as línguas orais - e "são adquiridas, processadas e representadas no cérebro basicamente do mesmo modo que as línguas faladas" 4 (LILLO-MARTIN; GAJEWSKAY, 2014, p. 388, Trad. Carlos Roberto Ludwig).

Os estudos científicos específicos sobre as línguas de sinais iniciaram com as pesquisas de Willian Stokoe, na década de 1960, quando ele provou que a American Sign Language (ASL) constituía uma língua natural sistematizada linguisticamente. Assim, foi possível verificar que as línguas de sinais

[...] poderiam ser descritas e analisadas utilizando-se os mesmos procedimentos teóricos e metodológicos aplicados às línguas orais, também apresentavam a propriedade da articulação: os sinais eram compostos por um conjunto limitado de elementos mínimos que se recombinavam para a produção de um número ilimitado de sinais, constituindo um sistema de contrastes altamente produtivo e econômico (LEITE; QUADROS, 2014, p. $15)$.

A partir das investigações de Stokoe, outros trabalhos foram desenvolvidos, dando ênfase aos processos e fenômenos próprios das línguas de modalidade visual-espacial. Essas 
pesquisas, como destacam Leite e Quadros (2014, p. 15-6), são importantes para a ciência linguística em geral por duas razões:

a) por demonstrar que as línguas de sinais possuem propriedades fundamentais, de modo que podem ser analisadas em vários aspectos: fonético, fonológico, prosódico, morfológico, lexical, sintático, semântico, pragmático, textual;

b) por observar as diferenças e as semelhanças de organização nos níveis apresentados anteriormente, "contribuindo para o aprofundamento da teoria linguística e para o aprimoramento de suas aplicações sociais na vida da comunidade surda" (LEITE; QUADROS, 2014, p. 16). Lillo-Martin e Gajewskay (2014, p. 398, Trad. Carlos Roberto Ludwig) também destacam que:

[...] o estudo das línguas de sinais leva mais adiante o campo de pesquisa do que apenas o estudo das línguas faladas. Tal estudo amplia as margens do que é conhecido sobre a linguagem, contribuindo com informações vitais para uma visão ampliada do que é profundo e do que é superficial. Ambos os aspectos profundos e superficiais da língua são importantes e relevantes para a teoria linguística. Entender exatamente onde os efeitos da modalidade são encontrados é crucial para todos os aspectos ${ }^{5}$.

Os estudos desenvolvidos a respeito das línguas de sinais vão além da proposta estrutural, observando, ainda, fatores como: expressividade, construções semânticopragmáticas, observações cognitivo-perceptual, análises variacionais e sociolinguísticas, entre outras. Sobre a produção e recepção de discursos, Lillo-Martin e Gajewskay (2014, p. 398, Trad. Carlos Roberto Ludwig) explicam: "Se a linguagem é uma ilustração de como a mente funciona, ou um módulo especializado, entendê-la é crucial para compreender a cognição humana" ${ }^{6}$. Nesse aspecto, as pesquisas sobre as línguas de sinais têm muito a contribuir.

No caso do Brasil, as pesquisas com foco nas Libras tiveram início na década de 80 , com o trabalho de Ferreira-Brito (1984). A partir daí, outras importantes contribuições têm sido desenvolvidas pela mesma Ferreira-Brito $(1990,1995)$ e por outras pesquisadoras: Karnopp (1994, 1999), Quadros (1995, 1999, 2013, 2018), para citar algumas. A partir de 2012, pesquisas têm dado destaque à toponímia em Libras, como veremos na sequência do presente estudo. 


\title{
2 Os estudos toponímicos em Libras
}

No ato de nomear, os sujeitos nomeadores imprimem ao topônimo características culturais e estabelecem processos de relação entre o espaço e o sujeito nomeador que vão além da própria relação entre significante e significado, numa visão arbitrária do signo. Isso ocorre nas línguas em geral, independentemente de sua modalidade: oral-auditiva ou visualespacial. Descrever os processos de nomeação dos espaços em Libras é, portanto, importante para a descrição da referida língua de sinais, tanto em relação ao processo de formação morfológica do sinal toponímico, quanto à relação língua-cultura.

\subsection{A pesquisa precursora de Souza $\mathrm{Jr}$.}

Souza Jr. (2012) identificou, armazenou e analisou uma amostra diversificada de topônimos da Língua de Sinais Brasileira de cidades brasileiras de 13 estados, destacando a forma de expressão como os surdos nomeiam os lugares. Como o próprio pesquisador destaca:

\begin{abstract}
As Línguas de Sinais apresentam uma maneira distinta de nomear, uma vez que o referente, nomeado em um sistema linguístico de modalidade oral/auditivo, recebe uma nova atribuição de natureza sinalizada. Alternativamente, um nome próprio, pode ser emprestado de uma língua oral para uma língua de sinais por meio de uso da transliteração do nome próprio pelo o alfabeto manual, também chamado datilológico. Contudo, geralmente um referente para um acidente geográfico (estado, cidade, país, bairro, rua etc.), ao ser incluído no cotidiano linguístico da comunidade surda, recebe um "sinal", que correferencia o indivíduo ou o lugar, em substituição ao nome próprio original e sua datilologia (SOUZA JR., 2012, p. 20).
\end{abstract}

Para atingir seu objetivo - registrar as características linguísticas dos sinais nomeadores de espaços e distribuir a frequência de dados de acordo com os fatores motivacionais - Souza Jr. partiu da proposta metodológica de Dick (1990), observando as questões relacionadas à identificação dos elementos que formam o signo toponímico e considerando as características da língua de sinais em foco, como se vê na figura 1: 
Figura 1: Estrutura dos topônimos em línguas de sinais

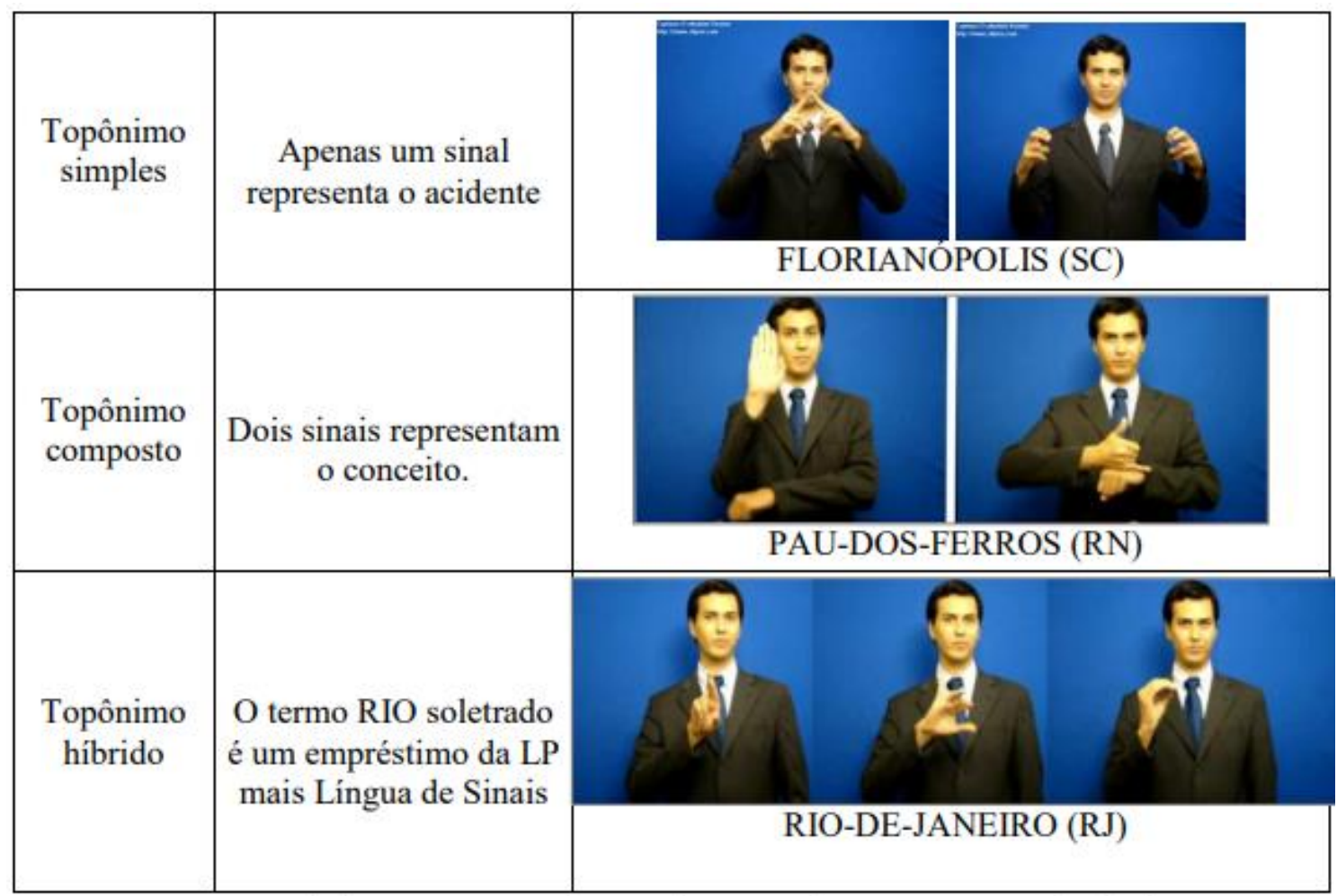

Fonte: Souza Jr. (2012, p. 28).

Para a análise motivacional dos sinais toponímicos, coletados a partir de 20 colaboradores informantes e 25 colaboradores na validação dos dados, Souza Jr. (2012) utilizou o modelo metodológico de classificação de Dick (1990) que apresenta 27 taxes, sendo 16 de natureza física e 11 de natureza antropocultural. $\mathrm{O}$ método da toponimista distribui e agrupa os topônimos a partir do campo semântico do qual cada lexema faz correspondência.

Para o armazenamento dos dados, Souza Jr. (2012) partiu da ficha lexicográficotoponímica proposta por Dick (2004) e fez acréscimos e supressões com o objetivo de contemplar as características descritivas das línguas de sinais, como por exemplo: a representação imagética do sinal frame-a-frame, a escrita do sinal em ELiS - um sistema de escrita alfabética das línguas de sinais desenvolvido por Mariângela Estelita (BARROS, 2008) - estrutura do topônimo em língua de sinais, classificação taxionômica do topônimo em língua de sinais etc., conforme figura 2: 
Figura 2: Ficha lexicográfico-toponímica de Souza Jr. (2012).

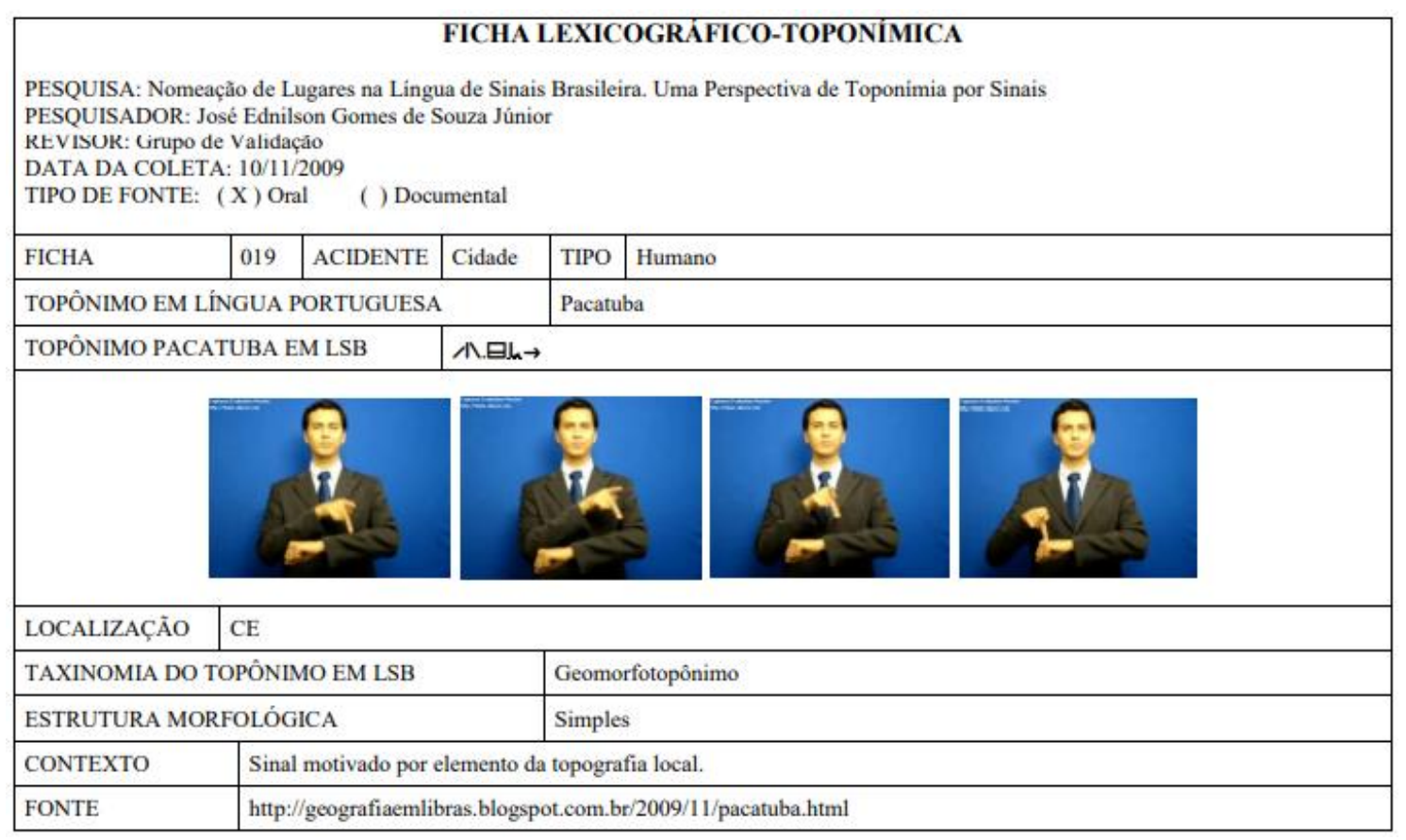

Fonte: Souza Jr. (2012, p. 99).

Pode-se afirmar que o estudo de Souza Jr. (2012) é precursor no que se refere à análise toponímica em língua de sinais no Brasil. O corpus utilizado pelo pesquisador, 265 sinais toponímicos, refletiu, de modo especial, a diversidade motivacional presente na Língua de Sinais Brasileira - LSB.

Com relação à frequência, $64 \%$ das taxes analisadas foram de natureza antropocultural, $13 \%$ de natureza física e $23 \%$ das taxes foram opacas quanto aos aspectos motivacionais de nomeação dos sinais toponímicos coletados.

Outra contribuição importante do estudo de Souza Jr. (2012) foi a observação de que "124 topônimos foram motivados integral ou parcialmente pela grafia do nome original do acidente geográfico denominado; constituíam unidades lexicais derivadas de empréstimos lingüísticos" (SOUZA Jr., 2012, p. 59). Esta verificação foi impulsionadora para a criação, pelo pesquisador, de uma nova taxe: grafotopônimo.

[...] o termo 'grafotopônimo' passa a qualificar os elementos específicos de topônimos motivados pela grafia do nome original do lugar, ou acidente geográfico. Sendo taxe que qualifica uma produção imaterial da cultura humana de caráter linguístico, esta taxe vincula-se à subcategoria das taxes antropo-culturais. [...] A taxe 'grafotopônimo' pode ser objeto de um estudo específico onde os topônimos sejam analisados a partir das características da 
motivação segundo as diferentes formas que o empréstimo pode ocorrer, podendo gerar novas sub-categorias (SOUZA Jr., 2012, p. 60).

Enfim, a ampla pesquisa demonstrou que as características onomásticas em línguas de sinais são semelhantes às das línguas orais, guardados os reflexos "da visão de mundo, história e cultura material e imaterial partilhados pelos surdos” (SOUZA Jr., 2012, p. 61).

\subsection{As pesquisas toponímicas em Libras no estado do Acre}

No estado do Acre, no âmbito do Projeto Atlas Toponímico da Amazônia Ocidental Brasileira (ATAOB), os estudos toponímicos têm sido desenvolvidos desde 2008. A partir de 2014, o projeto passou a inserir os topônimos em Libras que nomeiam os espaços geográficos que formam o estado do Acre. Essa inserção possibilitou o desenvolvimento de pesquisas dando ênfase, descrevendo e analisando os dados topomímicos em língua de sinais, como explicam Sousa e Quadros (2019a).

Algumas pesquisas iniciais merecem destaque: entre 2015 e 2017, Manuella Trindade Bezerra, no estudo Formação dos sinais toponímicos acreanos, desenvolveu análise preliminar dos sinais que nomeiam os municípios do estado do Acre e destacou os principais processos de formação dos sinais toponímicos. Esse estudo continuou em etapa posterior com o projeto Sinais toponímicos do Acre: a iconicidade no processo de formação. Os dados foram apresentados em Seminários do Programa de Iniciação à Docência (Pibic/UFAC) e no Seminário do GTLex.

Vicharlisson Brito Alemão, com base nos dados coletados em pesquisas anteriores, construiu um programa para armazenamento e processamento dos dados em Libras. A pesquisa intitulada Projeto ATAOB: armazenamento e dados em Libras contribuiu para a primeira versão da ficha digital, que destacava as especificidades linguísticas das línguas de sinais e dava a possibilidade de armazenar vídeos em Libras, incluir a escrita de sinais (Sign Writing) entre outros dados relevantes. A pesquisa foi desenvolvida entre 2017 e 2019.

Vale destacar que, em todas as etapas dos estudos desenvolvidos no Projeto ATAOB que consideravam a Libras, participaram pesquisadores surdos (do Centro de Apoio ao Surdo do Acre, da Licenciatura em Letras Libras da Universidade Federal do Acre, da comunidade em geral) e Tradutores Intérpretes de Língua de Sinais vinculados ao NAI (Núcleo de Apoio ao Surdo) e à Licenciatura em Letras Libras/UFAC. 
Sousa (2018), partindo dos estudos de Dick (1990, 1992) e dos estudos voltados para o léxico em Libras, propõe uma metodologia para os estudos toponímicos em Libras, considerando as especificidades línguo-culturais inerentes aos sujeitos nomeadores dos espaços. O trabalho foi elaborado como projeto submetido e aprovado no CNPQ (Processo $\mathrm{n}^{\circ}$ 104249/2018-8) e no Programa de Pós-Graduação em Linguística para desenvolvimento de Pós-Doutorado na Universidade Federal de Santa Catarina, na área de Linguística Aplicada/Libras - estágio que possibilitou trabalhos no campo da Toponímia em Libras, em parceria com a Dra. Ronice Müller de Quadros, supervisora da pesquisa.

Em Sousa e Quadros (2019b), os autores apresentaram o processo de constituição da ficha lexicográfico-toponímica digital para o estudo da toponímia em línguas de sinais. Partindo do modelo de ficha lexicográfico-toponímica de Dick (2004), os pesquisadores fizeram adaptações (acréscimos e supressões), considerando as especificidades linguísticoculturais próprias das línguas de sinais, que possuem modalidade visual-espacial (QUADROS; KARNOPP, 2004; QUADROS, 2019). A ficha proposta permite sistematizar os sinais coletados (topônimos em Libras) a partir de elementos como: sinal toponímico e aspecto motivacional (ambos em vídeos), estrutura fonológica e morfológica do topônimo (em escrita de sinais), referente motivacional (em imagem), localização geográfica (Google Maps), entre outros elementos que valorizam a língua e a cultura surdas, conforme a figura 3:

Figura 3: Ficha lexicográfico-toponímica de Sousa e Quadros (2019b).

\section{Toponímia em Libras - Acre}

Localização

Acidente Geográfico

Topônimo em Libras

Classificação

Taxonômica

Descrição da sinalização
https://goo.gl/maps/d6PUA1pD7RELPNHFA

A.H. Município

http://arquivos.nals.cce.ufsc.br/corpus/toponi

mia_em_libras/TA_SIN.mp4

Fitotopônimo

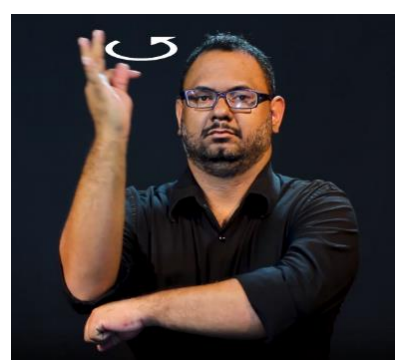




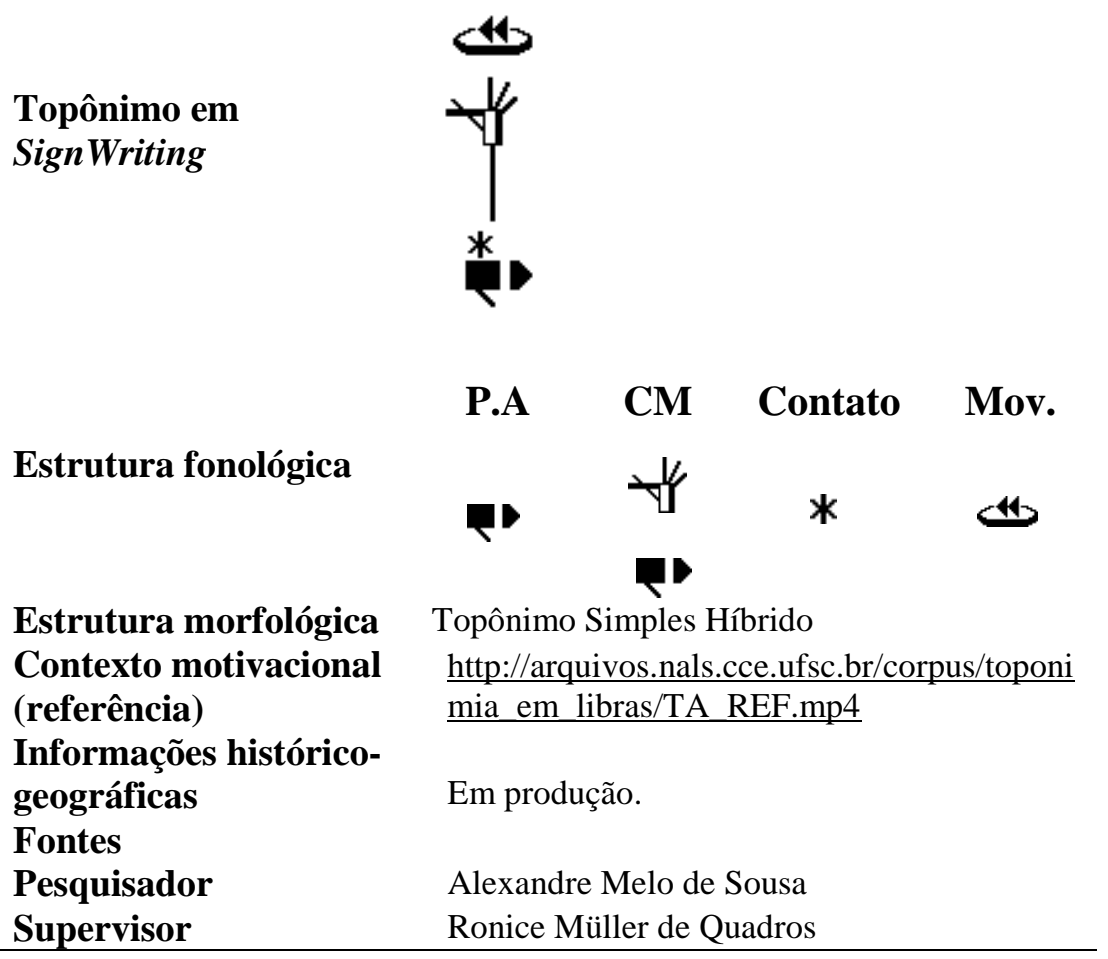

Fonte: Projeto Proposta metodológica para o estudo toponímico em Língua Brasileira de Sinais (UFSC/UFAC/CNPq).

Com os dados devidamente armazenados, Sousa (2019) passou a descrever os sinais e analisá-los, tomando como base as orientações teórico-metodológicas de Dick $(1990,1992)$ e as características linguísticas da Libras. Consta no relatório final do pós-doutoramento três observações principais:

a) Nos dados apresentados foi considerada a formação do topônimo em termo genérico e termo específico, uma vez que todos os informantes fizeram referência ao termo genérico (relacionado ao acidente geográfico propriamente dito) antes de apresentar o termo específico (sinal que particulariza o acidente), como mostrado a seguir.

Figura 4: Sinal toponímico - termo genérico e termo específico.

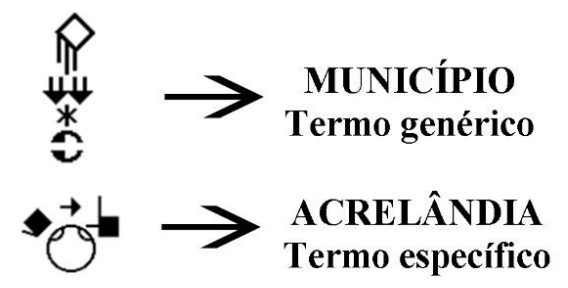

Fonte: Sousa (2019). 
b) Os dados coletados em Libras e analisados consideraram as seguintes possibilidades de formação do sinal toponímico: simples (quando possui um único formante em língua de sinais), simples híbrido (quando possui um único formante em língua de sinais, contudo, o formante possui configuração influenciada por letras da língua oral), composto (quando possui mais de um formante e todos os elementos da mesma língua de sinais) ${ }^{7}$, composto híbrido (quando possui mais de um formante, de línguas diferentes, como letras das línguas orais).

Figura 5: Estrutura de formação do Sinal Toponímico.

\begin{tabular}{|c|c|c|}
\hline $\begin{array}{c}\text { TERMO } \\
\text { ESPECÍFICO }\end{array}$ & $\begin{array}{c}\text { TIPO DE } \\
\text { FORMAÇÃO }\end{array}$ & DESCRIÇÃO \\
\hline & $\begin{array}{l}\text { Formação } \\
\text { Simples }\end{array}$ & $\begin{array}{l}\text { O termo específico SENA MADUREIRA é } \\
\text { estruturado por um sinal na língua nativa } \\
\text { (Libras): dedo indicador em movimentos } \\
\text { circulares apontando para a boca (fazendo } \\
\text { referência ao mandi, peixe próprio da região) }\end{array}$ \\
\hline & $\begin{array}{c}\text { Formação } \\
\text { Simples } \\
\text { Híbrida }\end{array}$ & $\begin{array}{l}\text { O termo específico TARAUACÁ é estruturado } \\
\text { por um sinal que apresenta, em sua formação, a } \\
\text { configuração em T (letra inicial do topônimo } \\
\text { em língua oral) }\end{array}$ \\
\hline 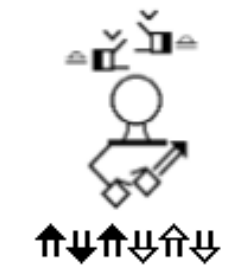 & $\begin{array}{l}\text { Formação } \\
\text { Composta }\end{array}$ & $\begin{array}{l}\text { O termo específico } \mathrm{ACRE}^{10} \text { é estruturado por } \\
\text { dois sinais, ambos em lingua nativa (Libras): } \\
\text { sinal ESTRELA + sinal ESPADA }\end{array}$ \\
\hline 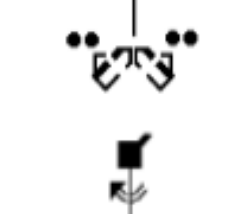 & $\begin{array}{c}\text { Formação } \\
\text { Composta } \\
\text { Híbrida }\end{array}$ & $\begin{array}{l}\text { O termo específico JORDÃO é estruturado por } \\
\text { dois sinais: um com a configuração em J (letra } \\
\text { inicial no topônimo em língua oral) seguido de } \\
\text { outro em língua nativa (sinal BARCO) }\end{array}$ \\
\hline
\end{tabular}

Fonte: Sousa (2019).

c) Os dados mostraram uma característica quanto à formação dos topônimos em Libras dos municípios acreanos: algumas configurações relacionadas às letras das línguas orais mostravam-se incorporadas ao sinal toponímico do município, enquanto outras eram independentes na estrutura de formação. 
Sousa e Quadros (2019c), como resultado do projeto, dedicaram espaço às contribuições que o estudo da toponímia em Libras pode oferecer à educação de surdos, e desenvolveram, ainda, o Web Software Toponímia em Libras, que apresenta os sinais dos municípios acreanos em Libras, os referentes motivadores de cada sinal, a estrutura fonológica do sinal em SignWriting, e a localização do município, por meio do Google Maps. Todo o software está em Libras, com vídeos instrucionais e segue os padrões de acessibilidade e as diretrizes de produção dos vídeos, podendo ser livremente acessado pelo endereço: http://www.toponimialibras.com (SOUSA; QUADROS, 2019d).

Figura 6: Web Software Toponímia em Libras.

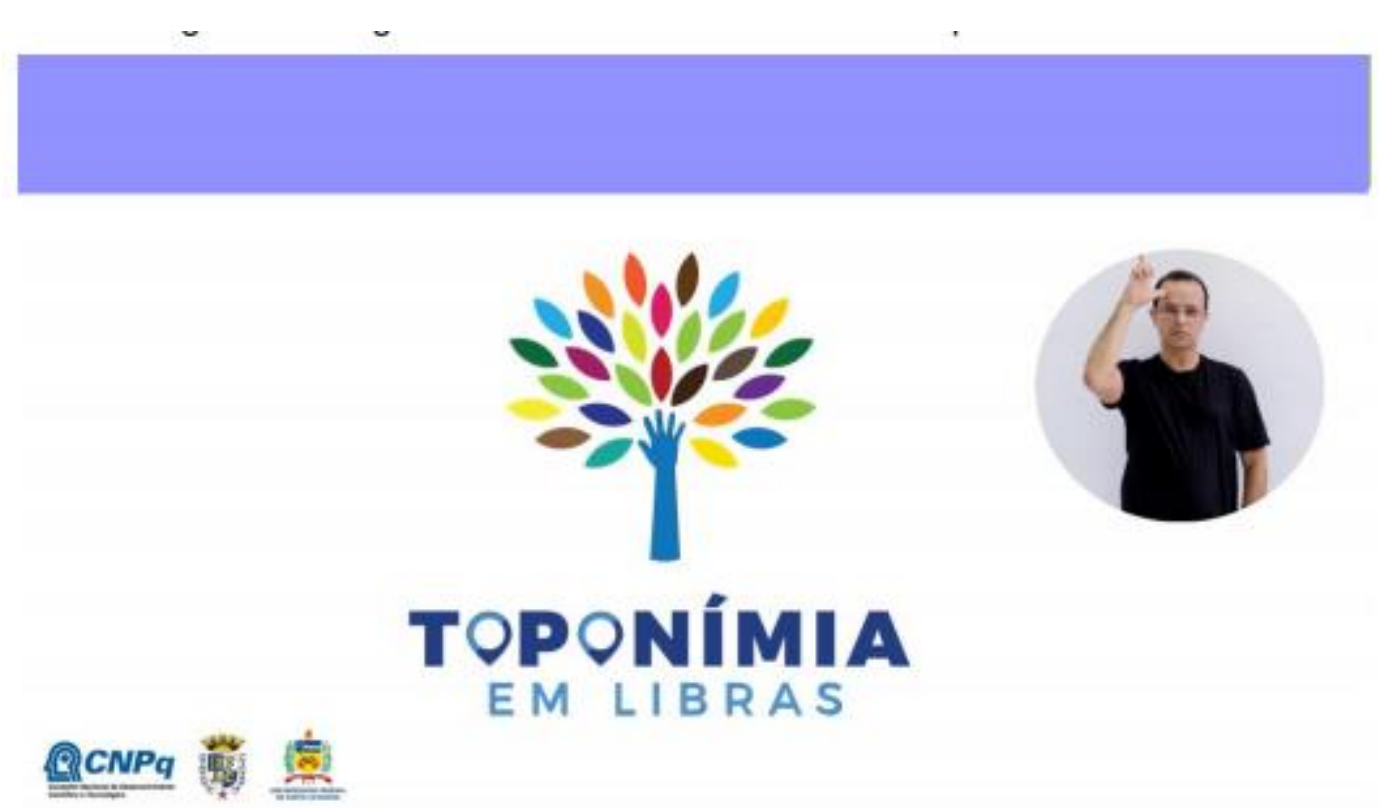

Fonte: Sousa e Quadros (2019d, p. 28).

Em outro estudo, Sousa (2020) analisou os topônimos em Libras dos bairros de Rio Branco. O corpus foi formado a partir de entrevistas, em vídeos, com cinco surdos de Rio Branco, pertencentes à comunidade acadêmica do curso de Letras Libras da Universidade Federal do Acre: quatro alunos e um professor. Dos 134 bairros que compõem as 10 regionais de Rio Branco, o autor identificou sinais toponímicos de 40 bairros.

Os dados foram analisados quanto aos aspectos estruturais e motivacionais. Em relação aos aspectos estruturais, os resultados mostraram forte influência da língua portuguesa escrita, uma vez que a maioria dos sinais apresenta, em sua formação fonomorfológica, as configurações de mãos referentes às letras dos nomes dos bairros na língua oral. O processo 
de empréstimo da língua oral (transliteração pragmática, transliteração lexicalizada e transliteração da letra inicial) favoreceu dois tipos de formação nos dados analisados: formação simples híbrida e formação composta híbrida.

Quanto aos aspectos motivacionais, a análise constatou que 11 sinais toponímicos em Libras foram motivados por referentes de natureza física, e 29 sinais toponímicos foram motivados por referentes de natureza antropocultural. Os aspectos relacionados à estrutura dos topônimos em Libras têm relação direta com os fatores motivacionais, estritamente visuais de representação icônica refletidos no ato da produção do sinal toponímico.

As pesquisas no Acre, quanto à toponímia em Libras, continuam buscando somar com as pesquisas realizadas anteriormente e colaborando na construção teórico-metodológica desta área e com os estudos linguísticos, de modo geral.

\subsection{As pesquisas toponímicas em Libras em Feira de Santana - Bahia}

As pesquisas toponímicas em Libras que vêm sendo desenvolvidas em Feira de Santana-BA estão atreladas ao projeto de pesquisa Estudo bilíngue da toponímia de Feira de Santana-BA: Português-Libras (CONSEPE-UEFS 044/2018), vinculado à Universidade Estadual de Feira de Santana (UEFS) e coordenado por Liliane Lemos Santana Barreiros. O intuito do projeto é comparar a motivação toponímica em Língua Portuguesa com a criação dos sinais em Libras para compreender as influências sócio históricas e as interfaces entre as línguas no processo de nomeação de espaços como: bairros, distritos, ruas, patrimônio material tombado, lagoas, feiras livres, instituições públicas, instituições religiosas, escolas, universidades, pontos turísticos, cemitérios, conjuntos residenciais, museus, parques, teatros etc., para aperfeiçoar o acesso do sujeito surdo.

Os dados da pesquisa estão sendo coletados nas Folhas Cartográficas do IBGE, no Instituto do Patrimônio Artístico e Cultural da Bahia (IPAC), na Secretaria Municipal de Desenvolvimento Urbano de Feira de Santana (SEDUR), na Secretaria Municipal de Trabalho, Turismo e Desenvolvimento Econômico (SETTDEC), no Museu Casa do Sertão, no Centro de Documentação e Pesquisa da UEFS e na comunidade surda de Feira de Santana.

Como aporte teórico-metodológico, o referido projeto de pesquisa segue o modelo taxionômico proposto por Dick (1992) e adaptado por Isquerdo (1996), Lima (1997), Francisquini (1998) e Souza Jr. (2012) para registrar e classificar os topônimos referentes aos bairros de Feira de Santana. O modelo de ficha lexicográfico-toponímica utilizada tem 
permitido sistematizar os dados coletados referentes à origem, à formação linguística, à intencionalidade, à motivação, aos aspectos históricos, culturais e sociais que influenciaram a criação dos nomes em Língua Portuguesa e dos sinais em Libras. A seguir, apresenta-se no quadro 1 o modelo da ficha e descreve-se os elementos que a compõem.

Quadro 1: Modelo de ficha lexicográfico-toponímica adotado em Feira de Santana-BA.

\begin{tabular}{|l|l|}
\hline \multicolumn{1}{|c|}{ FICHA LEXICOGRÁFICO-TOPONÍMICA BILÍNGUE } & NÚMERO: 01 \\
\hline TERMO GENÉRICO: O que é nomeado & TOPÔNIMO EM LP: Nome próprio do local \\
\hline TIPO DE ACIDENTE: Humano ou Físico & LOCALIZAÇÃO: \\
\hline TAXONOMIA DO TOPÔNIMO EM LÍNGUA PORTUGUESA: Indica a classificação. \\
\hline $\begin{array}{l}\text { ORIGEM: Indica a procedência do topônimo (Portuguesa, Africana, Indígena, Hibridismo, } \\
\text { Estrangeirismo). }\end{array}$ \\
\hline HISTÓRICO: Apresenta a evolução do topônimo, quando ocorreu. \\
\hline IMAGENS: Fotos do local ou algo que identifique. \\
\hline $\begin{array}{l}\text { INFORMAÇÕES ENCICLOPÉDICAS: Informações diversas sobre o topônimo a partir de } \\
\text { documentos oficiais. }\end{array}$ \\
\hline SINAL EM LIBRAS: Imagem da realização do sinal. \\
\hline TAXONOMIA DO TOPÔNIMO EM LIBRAS: Indica a classificação. \\
\hline $\begin{array}{l}\text { ESTRUTURA MORFOLÓGICA DO SINAL TOPONÍMICO: Descreve a composição do sinal } \\
\text { (simples, composto ou híbrido). }\end{array}$ \\
\hline CONTEXTO DO SINAL: Explica os aspectos motivacionais do sinal. \\
\hline FONTES: Indica as referências consultadas. \\
\hline
\end{tabular}

Fonte: Projeto de Pesquisa Estudo bilíngue da toponímia de Feira de Santana-BA: Português-Libras (UEFS-CONSEPE 044/2018).

O referido projeto de pesquisa encontra-se na primeira etapa. Até o momento, foram identificados 96 bairros, organizados em regiões administrativas, sendo cinco no distrito sede, e oito correspondendo a cada um dos distritos: Distrito Gov. João Durval Carneiro (Ipuaçu); Distrito de Bonfim de Feira; Distrito de Maria Quitéria (São José); Distrito de Humildes; Distrito de Tiquaruçu; Distrito de Jaíba; Distrito Jaguara; e Distrito da Matinha. Os 96 bairros foram objeto de estudo da dissertação Estudo toponímico dos bairros de Feira de SantanaBA: línguas orais e Libras (JESUS, 2019). Além dos bairros e distritos, inventariou-se 63 ruas do centro comercial e 5 avenidas de Feira de Santana, objeto de estudo da dissertação Estudo toponímico do centro comercial de Feira de Santana-BA: línguas orais e Libras (FERREIRA, 2019). Essa pesquisa está sendo ampliada para as demais ruas dos bairros do município.

Atualmente, a agenda de trabalho do projeto de pesquisa está voltada para a análise das unidades de saúde, das instituições de ensino, das igrejas, das feiras livres realizadas nos bairros, das 63 praças públicas e dos 16 patrimônios materiais tombados. Os dados 
preliminares das pesquisas realizadas evidenciam que a maioria dos surdos de Feira de Santana enfrentam obstáculos para identificar os espaços. Geralmente, eles utilizam o empréstimo linguístico por inicialização ou a datilologia para se situar ou referenciam a partir de estabelecimentos que já possuem um sinal específico.

\subsection{Outras pesquisas toponímicas em Libras no Brasil}

Merecem destaque, ainda, no âmbito das pesquisas toponímicas em Libras, os estudos de Aguiar (2012), Ferreira e Xavier (2019), Urbanski, Xavier e Ferreira (2019), Carvalho, Cruz e Praça (2019) e Chaibue (2020).

Aguiar (2012) selecionou, descreveu e analisou os sinais relacionados às nomeações de espaços a partir de um banco de dados elaborado com o propósito de categorizar os sinais com base em aspectos como iconicidade e origem. Dessa forma, foi possível analisar as características fonológicas e semânticas dos sinais toponímicos constantes no Dicionário Enciclopédico Ilustrado Trilíngue da Língua de Sinais Brasileira (Deit-Libras) de Capovilla e Raphael (2001).

De posse dos 472 sinais do campo semântico "localidades geográficas" do DeitLibras, Aguiar (2012) selecionou apenas os sinais que nomeavam continentes e ilhas, países, estados, cidades, regiões e bairros de São Paulo. Assim, foram considerados 208 topônimos que foram, posteriormente, descritos em 252 entradas e analisados com base em 2 critérios: iconicidade e origem. Como explica a autora:

O critério iconicidade foi incluído para que, por meio dele, se pudesse capturar uma possível relação entre a forma do sinal e o lugar designado por ele. Mais precisamente, diferenciar sinais que apresentam alguma motivação em sua forma. A descrição de classificação desse critério será dada mais a frente, no tópico que trata da fundamentação teórica desta pesquisa. O outro critério, origem, foi incluído para que se diferenciassem, entre os sinais analisados, aqueles que advêm de empréstimos linguísticos feitos à língua portuguesa escrita por meio de duas formas: a inicialização ou a soletração manual (AGUIAR, 2012, p. 111).

Quanto à origem, Aguiar (2012, p. 111) subdivide em 2 grupos: sinais inicializados, que são "aqueles cuja configuração inicial represente a primeira letra da palavra no português", e sinais derivados, que "são sinais completamente soletrados ou sinais cuja soletração sofreu alterações para se adaptar a fonologia da libras”. 
Concluídas as análises, Aguiar (2012) verificou que, quanto ao critério iconicidade, das 252 entradas para os topônimos analisados, 45 sinais foram classificados como icônicos e 207 como não icônicos. Quanto ao critério origem, dos 252 sinais analisados, 161 topônimos apresentaram a configuração de mão correspondente ao alfabeto datilológico ou numérico em Libras; enquanto 91 sinais toponímicos apresentavam outras configurações.

Quando observados os sinais que possuem configuração datilológica ou numérica, Aguiar (2012, p. 19-20) verificou que predominam os sinais inicializados: 88,55 - o que revela uma forte influência da língua portuguesa na criação dos sinais toponímicos.

Ferreira e Xavier (2019) analisaram topônimos da Libras que nomeiam bairros de Curitiba - PR. Os dados foram coletados em uma igreja católica da Pastoral do Surdo da Arquidiocese de Curitiba, frequentada por muitos surdos idosos, moradores antigos da área geográfica de interesse. Participaram 32 informantes, entre homens e mulheres, que tiveram suas identidades preservadas por razões éticas. A análise teve como base os estudos de Aguiar (2012) e Souza Jr. (2012), descritos anteriormente.

Dos 44 bairros apresentados por Ferreira e Xavier (2019), 37 possuem sinais. Deste total, os pesquisadores verificaram ocorrências de sinais nativos e de empréstimos do português. Com relação aos empréstimos, os dados mostraram casos de hibridismos, soletração e inicializações. Além disto, os resultados observados nos dados coletados pelos pesquisadores foram relacionados aos casos de variações de sinais em nível fonológico, morfológico e lexical.

Urbanski, Xavier e Ferreira (2019), por sua vez, pesquisaram os sinais toponímicos em Libras que nomeiam os municípios do Paraná. A pesquisa tomou como base, também, os estudos de Aguiar (2012) e Souza Jr. (2012).

Dos 399 municípios do estado do Paraná, apenas 64 têm sinal em Libras. Os dados foram coletados na Pastoral do Surdo da Arquidiocese de Curitiba e na Associação de Surdos do Paraná e, em seguida, filmados no estúdio do Curso de Licenciatura em Letras Libras da UFPR e acrescentadas legendas em escrita de sinais.

Os dados analisados por Urbanski, Xavier e Ferreira (2019) mostraram forte influência do português na criação dos sinais toponímicos em Libras dos municípios paranaenses. Foram preponderantes os casos de hibridismos, de soletração e de inicializações na formação dos topônimos analisados. Os sinais híbridos foram os mais frequentes. 
Carvalho, Cruz e Praça (2019) pesquisaram sobra a motivação, formação e usos de sinais da categoria países. Foram analisados sinais de nove países: Argentina, Austrália, Brasil, China, Cuba, Escócia, Holanda, Índia e Marrocos. Segundo as autoras, após a análise "pode-se destacar como aspectos motivacionais principais que influenciam na criação de léxicos/sinais o seguinte: situações de empréstimos linguísticos (intra e interlinguísticos), fatores culturais, semânticos e situações de iconicidade" (CARVALHO; CRUZ; PRAÇA, 2019, p. 169).

A referida pesquisa mostrou, ainda, empréstimos da língua portuguesa, "confirmando a existência de influências interlinguísticas entre o Português escrito e o sinal em Libras" (CARVALHO; CRUZ; PRAÇA, 2019, p. 183), e relações icônicas que expressam "a visão sociocultural da comunidade surda do Brasil em relação aos países ou mais propriamente em relação aos povos representados no processo de formação de sinais" (CARVALHO; CRUZ; PRAÇA, 2019, p. 184). Segundo as autoras, as análises desenvolvidas

[...] possibilitaram um olhar mais sensível para a motivação na lexicogênesis na Libras e como estas motivações são averiguadas na estrutura gramatical dessa língua, podendo desencadear outras discussões no campo da morfologia, semântica e fonologia, dentre outros tipos de estudos linguísticos nas línguas de sinais (CARVALHO; CRUZ; PRAÇA, 2019, p. 185)

Chaibue (2020), por seu turno, pesquisou os sinais em Libras da cidade de Formosa, GO. O corpus foi constituído por pesquisas na Internet e através de observações de conversação, com o registro de fremes de sinalização de membros da comunidade surda local, do Distrito Federal e de Goiânia. A análise revelou quatro sinais diferentes usados para nomear o município e a influência da língua portuguesa na estrutura dos sinais.

Em Ludwig at al (2020, p. 23), encontramos notícias sobre a pesquisa de Roselba Miranda, intitulada Pesquisa sobre topônimos da Libras, cujo objetivo é identificar e catalogar os topônimos da Libras em uso do estado do Tocantins. O estudo em tela está em desenvolvimento no âmbito do Programa de Pós-Graduação da Universidade Federal do Tocantins, e constitui um subprojeto do Inventário da Libras da Região de Palmas - TO, em desenvolvimento na mesma Instituição de Ensino Superior. 


\title{
Considerações finais
}

A análise dos topônimos em línguas orais e em Libras tem evidenciado aspectos linguísticos e históricos relevantes da origem das cidades em estudo, pois traz à tona questões políticas e culturais que envolvem o processo de nomeação de uma localidade, uma vez que, nesse campo, trabalha-se com um léxico que conserva antigos estágios denominativos.

O presente estudo buscou fazer um levantamento das pesquisas toponímicas em Libras desenvolvidas no Brasil. Ao descrever as pesquisas, observamos que os resultados apresentam características próprias das línguas de modalidade visual-espacial, tanto na constituição fonomorfológicas dos sinais, quanto nos aspectos semântico-motivacionais inerentes à produção (criação) dos sinais toponímicos. Além disso, as pesquisas evidenciaram o papel da iconicidade presente nos sinais toponímicos.

Por fim, vale ressaltar que ainda há muito a se pesquisar a respeito do ato de nomear os espaços geográficos em Libras e que os estudos toponímicos em línguas de sinais, pelo caráter interdisciplinar inerente ao campo léxico de nomeação de lugares, têm muito a contribuir no conhecimento da relação entre língua e cultura, e quanto às questões identitárias refletidas nos usos da linguagem - tal como tem sido observado nos estudos toponímicos relacionados às línguas orais.

\begin{abstract}
Toponymy is the area of linguistics dedicated to the proper names of places. Toponymic studies related to oral-auditory languages are traditional in Brazil. In visual-spatial languages, however, they are rare. This article aims to provide an overview of the researches dedicated to toponymy in Libras in Brazilian territory, observing the contributions of each study and the future perspectives with regard to the area in question.
\end{abstract}

Keywords: Toponymy. Libras. Research. Brazil.

\section{Referências}

AGUIAR, M. C. Descrição e análise dos sinais topônimos em Libras. In: ALBRES, N. A.; XAVIER, A. N. (Org.). Libras em estudo: descrição e análise. São Paulo: FENEIS, 2012. p. 109-121. 
BARROS, M. E. ELiS - Escrita das Línguas de Sinais: proposta teórica e verificação prática. 192f. Tese (Doutorado em Linguística) - Centro de Comunicação e Expressão, Universidade Federal de Santa Catarina, Florianópolis, 2008.

BRASIL. Lei $\mathbf{n}^{0}$ 10.436, de 24 de abril de 2002. Dispõe sobre a Língua Brasileira de Sinais LIBRAS e dá outras providências. Disponível em: <http://www.planalto.gov.br /ccivil_03/leis/2002/110436.htm>. Acesso em: 22 ago. 2018.

CAPOVILLA, F. C.; RAPHAEL, W. D. Dicionário enciclopédico ilustrado trilíngue da língua de sinais brasileira. São Paulo: Edusp, 2001.

CARVALHO, A. G.; CRUZ, A.; PRAÇA, W. N. Toponímia na Libras: motivação, formação e uso dos sinais da categoria países. In: FARIA, J. G.; REZENDE, T. F. (orgs). Expressões sinalizadas. Goiânia: Cegraf UFG, 2019, p. 161-185.

CHAIBUE, K. Toponímia e Libras a partir do sinal de Formosa - GO. In: LIMA, Á. H. V.; PITA, J. R.; SOARES, M. E. (orgs.) A Linguística na teoria e na prática. São Paulo: Pimenta Cultural, 2020, p. 408-428.

CRASBORN, O. Phonetics. In: PFAU, R.; STEINBACH, M.; WOLL, B. (Eds.). Sign Language: An International Handbook. Berlin: De Gruyter, 2012, p. 4-20.

DICK, M. V. de P. Rede de Conhecimento e Campo Lexical: hidrônimos e hidrotopônimos na onomástica brasileira. In ISQUERDO, Aparecida N.; KRIEGER, Maria da Graça. As Ciências do Léxico: lexicologia, lexicografia e terminologia. Vol. II. Campo Grande: Editora UFMS, 2004.

DICK, M. V. de P. Toponímia e Antroponímia no Brasil. Coletânea de Estudos. São Paulo, FFLCH/USP, 1990.

DICK, Maria Vicentina P. Amaral. A motivação toponímica e a realidade brasileira. São Paulo: Arquivo do Estado, 1992.

FERREIRA, D.; XAVIER, A. N. Topônimos na Libras: análise preliminar de sinais que designam bairros de Curitiba. In: Trabalhos completos da XXI Semana de Letras. Universidade Federal do Paraná, 2019. Disponível em: https://drive.google.com/file/d/1C7P9PSCh9jVKrSBQtUXBmr_uKAQAYX9u/view. Acesso em: 10 de maio de 2020.

FERREIRA, D. B. dos S. Estudo toponímico do centro comercial de Feira de SantanaBA: línguas orais e Libras. 186f. Dissertação (Mestrado em Estudos Linguísticos) Universidade Estadual de Feira de Santana, Feira de Santana, 2019.

FERREIRA-BRITO, L. Epistemic, Alethic, and Deontic Modalities in a Brazilian Sign Language. In: S.D. Fisher and P. Siple (eds.) Theoretical Issues in Sign Language Research. Vol. 1. University of Chicago Press. 1990.

FERREIRA-BRITO, L. Por uma gramática de línguas de sinais. Tempo Brasileiro. UFRJ. Rio de Janeiro, 1995. 
FERREIRA-BRITO, L. Similarities and Differences in Two Sign Languages. Sign Language Studies. 42: 45-46. Linstok Press, In: Silver Spring, USA, 1984.

FRANCISQUINI, I. de A. O nome e o lugar: uma proposta de estudos toponímicos da microrregião de Paranaval. Dissertação (Mestrado) - UEL. Londrina, PR, 1998.

ISQUERDO, A. N. O fato lingüístico como recorte da realidade sócio-cultural. Tese (Doutorado) - Universidade Estadual Paulista, São Paulo, 1996.

JESUS, C. M. A. de. Estudo toponímico dos bairros de Feira de Santana-BA: línguas orais e Libras. 169f. Dissertação (Mestrado em Estudos Linguísticos) - Universidade Estadual de Feira de Santana, Feira de Santana, 2019.

KARNOPP, L. B. Aquisição do Parâmetro Configuração de Mão dos Sinais da LIBRAS: estudo sobre quatro crianças surdas filhas de pais surdos. Dissertação de Mestrado. Instituto de Letras e Artes. PUCRS. Porto Alegre, 1994.

KARNOPP, L. B. Aquisição fonológica na Língua Brasileira de Sinais: estudo longitudinal de uma criança surda. Tese de Doutorado. PUCRS. Porto Alegre, 1999.

LEITE, T. A.; QUADROS, R. M. Línguas de Sinais no Brasil: reflexões sobre o seu estatuto de risco e a importância da documentação. STUMPF, M. R.; QUADROS, R. M.; LEITE, T. A. (orgs). Estudos da Língua Brasileira de Sinais II. Florianópolis: Editora Insular, 2014.

LILLO-MARTIN, D.; GAJEWSKAY, J. One grammar or two? Sign Languages and the Nature of Human Language, WIREs CognSci, 2014, 5, p. 387- 401.

LIMA, I. A. de. A motivação religiosa dos topônimos paranaenses. In: Estudos linguiísticos XLV Seminário do GEL. Campinas: UNICAMP, 1997.

LUDWIG, C. R. et al. Inventário da Libras do Tocantins: constituição e coleta de dados. Revista Desafios, 7 (1), 10-26, 2020. Disponível em: https://doi.org/10.20873/uftv7-5794 Acesso em: 23 de abril de 2020.

QUADROS, R. M. As categorias vazias pronominais: uma análise alternativa com base na língua de sinais brasileira e reflexos no processo de aquisição. Dissertação de Mestrado. PUCRS. Porto Alegre, 1995.

QUADROS, R. M. Contextualização dos estudos linguísticos sobre a Libras no Brasil. In: QUADROS, R. M.; STUMPF, M. R.; LEITE, T. A. (orgs). Estudos da Língua Brasileira de Sinais I. Florianópolis: Editora Insular, 2013.

QUADROS, Ronice Müller de. Língua de herança: Língua Brasileira de Sinais. Porto Alegre: Penso, 2017.

QUADROS, R. M. et al. Língua Brasileira de Sinais: patrimônio linguístico brasileiro. Florianópolis: Editora Garapuvu, 2018.

QUADROS, R. M. Libras. São Paulo: Parábola Editorial, 2019. 
QUADROS, R. M. Língua de herança: Língua Brasileira de Sinais. Porto Alegre: Penso, 2017.

QUADROS, R. M. Phrase structure of Brazilian sign language. Tese de Doutorado. PUCRS. Porto Alegre, 1999.

QUADROS, R. M.; KARNOPP, L. B. Língua de sinais brasileira: estudos lingüísticos. Porto Alegre: Artmed, 2004.

SOUSA, A. M.; QUADROS, R. M. Toponímia em Libras: aspectos formais e motivacionais dos sinais toponímicos dos municípios acreanos. In: CAVALHEIRO, J.; LUDWIG, C. R.; LANES, E. J. (org.). Lingu(agem), ensino e formação docente. Manaus: Editora UEA, 2019a.

SOUSA, A. M.; QUADROS, R. M. Proposta de ficha lexicográfico-toponímica digital para o estudo da toponímia em línguas de sinais. In: Revista Guavira. Três Lagoas/MS. v. 15. n. 30, p. 126-140, 2019b.

SOUSA, A. M.; QUADROS, R. M. Toponímia em Libras: tecnologia e ensino. Anais do Simpósio Ibero-Americano de Tecnologias Educacionais 2019. Araranguá (SC): Laboratório de Experimentação Remota (Rexlab), 2019c. p. 137-146. Disponível em: https://publicacoes.rexlab.ufsc.br/index.php/sited/article/view/131/17. Acesso em: 19 de março de 2020.

SOUSA, A. M.; QUADROS, R. M. O Web Software Toponímia em Libras: pesquisa e ensino. In: SOUSA, A. M.; GARCIA, R.; SANTOS, T. C. (org.). Perspectivas para o ensino de línguas 3. São Carlos (SP): Pedro \& João Editores, 2019d. Disponível em: https://ebookspedroejoaoeditores.wordpress.com/2019/09/13/perspectivas-para-o-ensino-delinguas-volume-3/. Acesso em: 19 de março de 2020.

SOUSA, A. M. Metodologia para a pesquisa toponímica em língua Brasileira de Sinais. In: SOUSA, A. M.; GARCIA, R.; SANTROS, T. C. Perspectivas para o ensino de línguas 2. Rio Branco: Nepan, 2018, p. 9-37.

SOUSA, A. M. Toponímia em Libras. Relatório (Pós-Doutorado - Linguística Aplicada/Libras) - Programa de Pós-Graduação em Linguística. Universidade Federal de Santa Catarina, UFSC, Florianópolis, 2019.

SOUSA, A. M. Toponímia em Libras dos bairros de Rio Branco: análise da estrutura dos sinais toponímicos e dos aspectos motivacionais. In: ISQUERDO, A. N. (org.). Toponímia urbana: estudos. Campo Grande, MS: Ed. UFMS, 2020. (no prelo)

SOUZA JR, J. E. G. Nomeação de lugares na língua de sinais brasileira: uma perspectiva de toponímia por sinais. Dissertação de Mestrado. Programa de Pós-graduação em Linguística. Universidade de Brasília - UnB. Brasília, 2012.

UEFS/CONSEPE. Resolução CONSEPE No 044/2018. Aprova o Projeto de Pesquisa Estudo bilíngue da toponímia de Feira de Santana-BA: Português-Libras, sob a coordenação da Profa. Dra. Liliane Lemos Santana Barreiros, do Departamento de Letras e Artes, desta Universidade. Feira de Santana-BA: D.O.E., 13 abr. 2018. 
URBANSKI, I. R. W.; XAVIER, A. N.; FERREIRA, D. Topônimos na Libras: análise preliminar de sinais que nomeiam cidades do estado do Paraná. In: Trabalhos completos da XXI Semana de Letras. Universidade Federal do Paraná, 2019. Disponível em: https://drive.google.com/file/d/1C7P9PSCh9jVKrSBQtUXBmr_uKAQAYX9u/view. Acesso em: 10 de maio de 2020.

\section{Notas}

${ }^{1}[\ldots]$ are produced by body movements that are perceived visually (CRASBORN, 2012, p. 4).

${ }^{2}[\ldots]$ are produced by vocal articulation and perceived by the ear (CRASBORN, 2012, p. 4).

${ }^{3}$ Since auditory perception is better targeted at processing small temporal detail than visual perception, and since the manual articulators in signing move slower than the oral articulators in speech, one would for example predict the richness of simultaneous information in sign languages (CRASBORN, 2012, p. 4).

${ }^{4}[\ldots]$ they are acquired, processed, and represented in the brain in largely the same way as spoken languages are (LILLO-MARTIN; GAJEWSKAY, 2014, p. 388).

${ }^{5}[\ldots]$ the study of sign languages takes the field farther ahead than the study of spoken languages alone. Such study pushes the edges of what is known about language, contributing vital information to an expanding vision of what is deep and what is surface. Both deep and surface aspects of language are important and relevant to linguistic theory. Understanding just where modality effects are found is crucial for all aspects (LILLOMARTIN; GAJEWSKAY, 2014, p. 398).

${ }^{6}$ Whether language is an illustration of how the mind works, or a specialized module, understanding it is crucial to understanding human cognition (LILLO-MARTIN; GAJEWSKAY, 2014, p. 398).

7 No corpus analisado não apareceram topônimos compostos “puros”. 